\title{
8
}
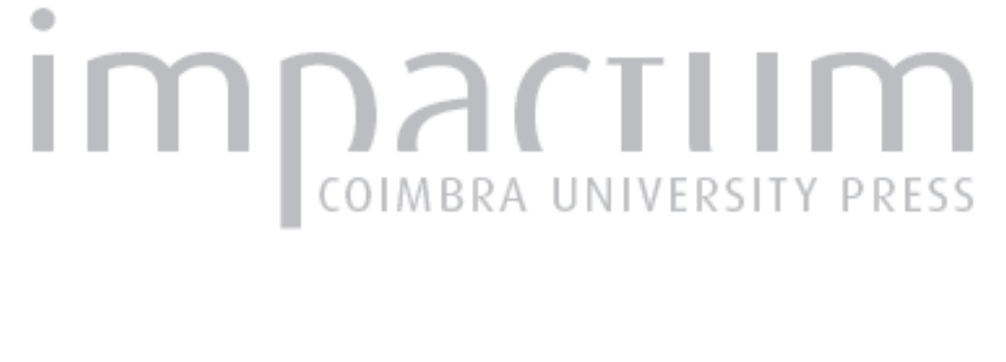

\section{Viagens do olhar europeu sob a herança do filosofar: do movimento da theoria ao olhar vazio de Narciso}

Autor(es): $\quad$ Portocarrero, Maria Luísa Publicado por: Faculdade de Letras da Universidade de Coimbra, Instituto de Estudos

URL

persistente:

DOI: DOI:http://dx.doi.org/10.14195/0872-0851_37_1

Accessed : $\quad$ 26-Apr-2023 14:40:24

A navegação consulta e descarregamento dos títulos inseridos nas Bibliotecas Digitais UC Digitalis, UC Pombalina e UC Impactum, pressupõem a aceitação plena e sem reservas dos Termos e Condições de Uso destas Bibliotecas Digitais, disponíveis em https://digitalis.uc.pt/pt-pt/termos.

Conforme exposto nos referidos Termos e Condições de Uso, o descarregamento de títulos de acesso restrito requer uma licença válida de autorização devendo o utilizador aceder ao(s) documento(s) a partir de um endereço de IP da instituição detentora da supramencionada licença.

Ao utilizador é apenas permitido o descarregamento para uso pessoal, pelo que o emprego do(s) título(s) descarregado(s) para outro fim, designadamente comercial, carece de autorização do respetivo autor ou editor da obra.

Na medida em que todas as obras da UC Digitalis se encontram protegidas pelo Código do Direito de Autor e Direitos Conexos e demais legislação aplicável, toda a cópia, parcial ou total, deste documento, nos casos em que é legalmente admitida, deverá conter ou fazer-se acompanhar por este aviso. 


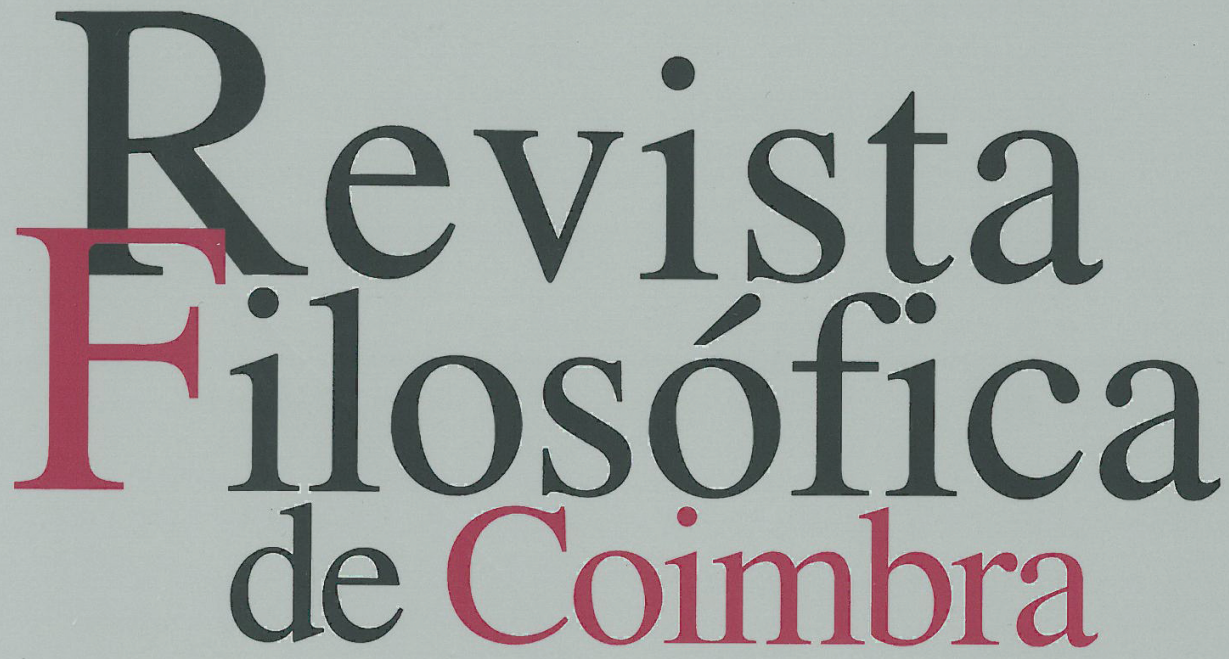

vol.19|n. $.37 \mid 2010$

Maria Luísa Portocarrero Mário Santiago de Carvalho Alexandre Franco de Sá Luís António Umbelino Luís G. Soto José Filipe Silva Joaquim Braga Maria da Conceição Camps Pedro Miguel Panarra Immanuel Kant 


\title{
VIAGENS DO OLHAR EUROPEU SOB A HERANÇA DO FILOSOFAR: DO MOVIMENTO DA THEORIA AO OLHAR VAZIO DE NARCISO.
}

\author{
MARIA LUÍSA PORTOCARRERO*
}

\begin{abstract}
Resumo: Este artigo parte da tese husserliana segundo a qual foi o desenvolvimento da filosofia, na Grécia antiga, que deu origem ao modo de estar no mundo chamado Europa. Sustenta a tese de que a crise actual da Europa está associada à desvalorização e transformação do sentido do fílosofar, pelo império dos cientismos e de uma tecnociência que governa o mundo sem ser acompanhada pelo desenvolvimento do pensamento ético-filosófico.
\end{abstract}

Palavras-chave: Europa, Filosofia, Teoria, a Ideia de uma Europa Filosófica.

\section{E. Husserl ou a relação entre Europa e Filosofia}

Vamos neste texto partir da Europa como uma forma crítica do pensar e não como espaço meramente geográfico ou económico político e analisá-la sob o signo da viagem, não a do mito da Europa, nem a do entretenimento, a que estamos hoje habituados. Referimo-nos, pelo contrário, à viagem interior, espiritual, que aconteceu na Grécia dos sécs. VII e VI antes de Cristo e que inaugurou a crise ou espanto filosófico que marcou toda a diferença da Europa. Partiremos, é claro, da tese célebre de E. Husserl, a da sua conferência «A crise da humanidade europeia e a filosofia» (1935) segundo a qual Europa e filosofia são sinónimas, o que significa que o conceito de Europa não tem, para o filósofo, uma definição meramente territorial, nem deve ser compreendido «de forma cartográfica,

* Departamento de Filosofia, Comunicação e Informação (Faculdade de Letras da Universidade de Coimbra). 
como se, com isso, fosse delimitado, enquanto humanidade europeia, apenas o círculo dos homens que aqui vivem territorialmente, em conjunto» ${ }^{1}$. A Europa representa, nas palavras de Husserl, o nascimento do espírito de crítica livre que mede todas as coisas pelo crivo das tarefas infinitas e que cria novas redes infinitas. Representa uma abertura infinita do olhar, uma forma de meditar que determinou uma idiossincrasia própria com reflexos políticos, antropológicos e sociais e que surgiu com a libertação feita pelos primeiros filósofos gregos do tempo do mito, enquanto forma de pensar. «Em todas as outras culturas o tempo dos homens é o tempo de Deus ou dos deuses. Só a cultura europeia pretendeu que o tempo dos deuses fosse o tempo dos homens» ${ }^{2}$, diz-nos também Eduardo Lourenço, e tal facto, deve-se à filosofia, enquanto viagem interior, movimento ou amor pela sabedoria.

Foram os primeiros filósofos, os da escola de Mileto, que suspenderam, de facto, a imaginação dramática do enredo mítico do mundo e iniciaram um novo modelo de inteligibilidade. Com eles, «explicar um fenómeno não pode mais consistir em nomear o seu pai e a sua mãe, isto é, em estabelecer a sua filiação. Se as realidades naturais apresentam uma ordem regular, isto não acontece porque um belo dia um deus soberano, no final dos seus combates se impôs aos outros deuses, à maneira de um monarca que, no seu reino, reparte os cargos, funções e domínios. A ordem deve ser pensada, para ser inteligível, como uma lei imanente à natureza e que preside, desde a sua origem, à sua organização» ${ }^{3}$.

Os primeiros filósofos têm o mérito de recusar as explicações genealógicas míticas da origem do mundo pelos feitos de divindades e de procurar, por detrás do fluxo aparente das coisas, os princípios abstractos permanentes que sustentam o equilíbrio dos diversos elementos que compõem o universo. Os filósofos de Mileto não fazem intervir nas suas explicações nenhum elemento sobrenatural. Pelo contrário, para eles a estranheza dos fenómenos, em vez de sugerir o sentimento do divino, propõe ao espírito humano um problema a pensar. Com eles a natureza invade, com a sua positividade, todo o campo do real: eles abrem, com a sua forma peculiar de pensar, um campo de investigação e de questionamento «em que a natureza é apreendida ao mesmo tempo em termos positivos, gerais e abstractos» ${ }^{4}$. Já não se trata de estabelecer uma intriga narrativa sobre a

${ }^{1}$ HUSSERL, E., «A crise da humanidade europeia e a filosofia» in IDEM, Europa: crise e renovação, trad. Lisboa, Centro de Filosofia, 2006, 123.

${ }^{2}$ LOURENÇO, E. «O nosso tempo e o tempo dos outros» in Jornal de Letras, 16-29 de Janeiro 2008, p.8.

${ }^{3}$ VERNANT, J,P., Mythe et pensée chez les Grecs, Paris, La Découverte, 1996, p. 406

${ }^{4}$ IDEM, ibidem, p. 406. 
origem do mundo mas de propor uma theoria, de construir conceitos, cujo significado não é visível em imagens, de conferir uma figura simbólica ao mundo, dando para isso a ver como as coisas se passam logicamente e projectando-as num quadro espacial ${ }^{5}$.

E não o esqueçamos, este advento da filosofia como espanto, crise e amor pela sabedoria, que dá origem à theoria, como movimento da alma que desenvolve a capacidade abstracta do pensar, não pode ser concebido sem o conjunto das transformações que, no séc. VI a. c., ocorreram nas sociedades gregas e que levaram ao nascimento da cidade estado, a polis. Com efeito, a filosofia começa por surgir como sabedoria, completamente marcada pela reflexão moral e pelas preocupações políticas. É no contexto de um mundo social marcado pela isonomia, pela igualdade em relação à lei que encontramos o novo modelo de mundo elaborado pelos filósofos de Mileto,

Europa e filosofia referem, pois, enquanto sinónimas, uma certa relação ao mundo, marcada pela viagem teorética, pela filosofia como questão, movimento ou anseio pelo saber, acerca das grandes questões da polis e da humanidade. Que perguntas são estas? Aquelas que são verdadeiramente origem do comum ou universal, que causam espanto e fazem surgir a distância perante o que imediatamente aflui, perante o meramente útil. Aquelas que surgem com o apartamento que liberta o homem de todo o cálculo, do âmbito do necessário e meramente útil, e que abre o caminho para o poder tomar parte ou partilhar do mundo dos conceitos, do Bem, do Belo, do Justo, isto é, daquele tipo de bens simbólicos universais, que não se reduzem mediante a participação, mas pelo contrário ganham com ela. Universais estes que as figuras degradadas do universalismo científico acabaram por ameaçar, na medida em que ocultaram o gesto filosófico e simbólico originário, o eros de que falava Platão. Isto é, um desejo ou uma consciência de infinito, cujo horizonte transcende toda a pretensão totalitária do universal que totaliza.

É na irrupção da viagem interior, de índole filosófica, na qual todas as ciências se encontram incluídas, pois surgiram a partir dela, que Husserl vê o fenómeno originário da Europa ${ }^{6}$. O ideal da vida teórica, que nos foi directamente transmitido pelo pensamento grego, teve sobretudo um significado simbólico e político ${ }^{7}$, que nos permite considerar a Europa como uma profunda unidade, apesar da sua múltipla e aparente diversidade. «Há na Europa um género único, de tal modo que apesar de qualquer hostilidade das nações europeias entre si, elas têm no entanto um

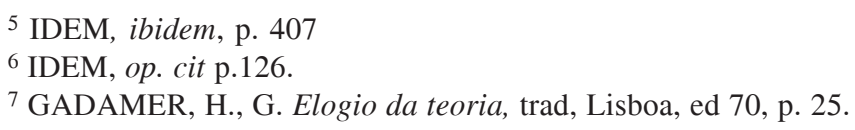


parentesco íntimo particular em espírito, parentesco que a todos atravessa e que transcende as diferenças nacionais. São nações irmãs». Nações irmãs no modo de ver e considerar o mundo, o homem, os céus e a terra, na sua curiosidade filosófica e científica e na sua afirmação da liberdade.

Resumamos então antes de avançar: de acordo com Husserl, com a aparição da viagem filosófica grega, surgiu um sentido de abertura espiritual infinita, a theoria que transcendeu o regionalismo das fronteiras das cidades estado e que constituiu uma mutação na forma de pensar tradicional, o mito ao qual ficaram presas outras culturas. A theoria foi, desde Platão um ideal educativo, derivado das formas institucionais e das estruturas mentais próprias da polis, isto é, o princípio da cultura escolar, cujos reflexos no espaço público, a Antiguidade clássica legou à Europa. Ela norteou todo o conjunto da cultura espiritual do Ocidente e da humanidade. Mas que atitude é esta afinal? O desejo de um saber desinteressado que conduz à contemplação e meditação sobre as questões essenciais ou grandes humano, enquanto ser no mundo. Theoria, diz- nos Gadamer significa: «estar entregue a algo que, em sua poderosa presença, se oferece a todos em conjunto que está caracterizado pelo seguinte: diferentemente do que acontece com todos os bens úteis, não se reduz mediante a participação e, portanto, não é codificado da mesma maneira que todos os outros bens, mas ganha com a participação. Este é, em última instância, o nascimento do conceito de razão: quanto mais algo se apresenta para todos como convincentemente desejável, tanto mais os homens tem liberdade, no sentido positivo, isto é, verdadeira identidade com o que é comum» ${ }^{8}$.

Só esta atitude teorética, isto é, não governada por interesses imediatos, pragmáticos particulares e conceitos concretos permite, segundo Husserl, abstrair de interesses particulares e visar fins racionais infinitos, aqueles que são mais visados do que possuídos, mas que tem a validade universal de uma questão eterna. O homem torna-se, com ela, um espectador desinteressado, um olhar teórico sobre o mundo, um filósofo, na opinião de Husserl ${ }^{9}$. Isto é, um ser marcado pela «peculiar universalidade da postura crítica, a qual está decidida a não aceitar sem questão qualquer opinião previamente dada, qualquer tradição, de modo a que possa perguntar, logo de seguida, (a respeito de todo o universo previamente dado, segundo a tradição), pelo que é em si verdadeiro, por uma idealidade» ${ }^{10}$. Um ser que distingue entre representação do mundo e mundo

${ }^{8}$ IDEM,Vernunft im Zeitalter der Wissenschaft. Aufsätze, Frankfurt, Suhrkamp, 1976, p. 64.

${ }^{9}$ Cf., HUSSERL., E., op. cit, p.136. 
efectivo e que pergunta pela verdade, não pela verdade do quotidiano, vinculada à tradição, mas antes por uma verdade válida para todos, os que não estão dominados pelo peso de tradições ${ }^{11}$. «Foram os Gregos que, em consequência da criação da Filosofia no seu sentido pregnante (platónico), implantaram na cultura europeia uma ideia formal universal, de novo tipo, pela qual ela adquiriu o carácter formal universal de uma cultura racional a partir da racionalidade científica, ou de uma cultura filosófica» 12

Foi tal atitude racional que apareceu pela primeira vez na Grécia, que permitiu ao homem libertar-se de condicionalismos particulares, ser livre, isto é, isento de preconceitos míticos e do peso de tradições não sujeitas ao crivo da crítica. Dela resultou diz-nos o filósofo, uma forma particular de humanidade e uma particular vocação de vida, correlativa de uma nova cultura. «O conhecimento filosófico do mundo não cria apenas resultados de tipo particular, mas cria, antes, uma postura humana que imediatamente engrena em toda a restante vida prática (...). Edifica-se entre os homens uma comunidade nova e íntima, poderíamos mesmo dizer, uma comunidade de puros interesses ideais - a dos homens que vivem a Filosofia, ligados entre si pela dedicação às ideias, que não são apenas úteis a todos, mas que são próprias de todos eles. A origem da ciência grega, lembra-nos Husserl, reside justamente no facto de homens singulares, com um interesse comum, a que chamamos puramente teórico, serem movidos pelo amor puro do conhecimento objectivo da verdade dada na intelecção. Para eles, a fixação duradoura da verdade adquirida e a estabilização desta sob forma literária não têm apenas o intuito do próprio sujeito poder dispor dela, mas pelo contrário, ela é sempre a premissa para novas verdades e o meio de transmissão a outros cujos interesses cognitivos são despertados e assim as mesmas intelecções e alegrias são compartilhadas ${ }^{13}$.

Necessariamente se formou uma eficiência comunitária de tipo particular (a filosofia), a do trabalhar com o outro e do trabalhar para o outro, mutuamente se coadjuvando no exercício crítico, a partir do qual resulta a verdade pura e incondicionada, enquanto bem comum». ${ }^{14}$ A atitude teórica tem nos Gregos a sua origem histórica ${ }^{15}$, refere-se retrospectivamente a uma atitude precedente que era, até então, a norma;

\footnotetext{
${ }^{10}$ IDEM, ibidem, p. 137.

11 IDEM, ibidem.

12 IDEM, «Tipos formais da cultura no desenvolvimento da humanidade» in, IDEM,
} Europa crise e renovação, p. 106.

13 IDEM, ibidem.

14 IDEM, «A crise da humanidade europeia e a filosofia» p.138.

15 IDEM, ibidem, p. 131. 
ela caracteriza-se enfim por uma conversão de postura, pela atitude de comunidade científica que se alarga naturalmente, para lá dos valores do conhecimento, «a valores novos e mesmo superiores que estão fundados no valor da própria ciência», os valores éticos, individuais e comunitários que crescem ${ }^{16}$.

Deste modo, na Europa a cultura da razão ultrapassou a cultura mítico religiosa e, apesar de possuirmos: «hoje em dia, uma profusão de trabalhos sobre a filosofia Indiana, a filosofia Chinesa, etc., nos quais estas são postas no mesmo plano que a filosofia Grega e são tomadas como simples enformações históricas diversas no interior de uma mesma ideia de cultura (...), não devemos permitir que o geral simplesmente morfológico encubra as profundezas intencionais e nos torne cegos para as mais essenciais diferenças de princípio». A atitude mítico-religiosa, que também na Grécia existiu, antes da Filosofia, consiste «em que o mundo, enquanto totalidade, se torna temático, e, decerto temático de modo prático; (....) a esta atitude mítica e natural pertencem de antemão e primeiro que tudo não apenas homens e animais e outros seres sub-humanos e sub-animais, mas também seres sobre-humanos. O olhar que os abarca, enquanto totalidade, é prático» ${ }^{17}$, isto é, constantemente dirigido para o restante mundo, enquanto é regulado pelos poderes míticos e pelo que lhes corresponde, enquanto o olhar do filósofo se abre ao infinito. Com efeito, Husserl frisa-o claramente: « (...) a Ciência e a Filosofia são, em primeiro lugar, mesmo não durante muito tempo, uma coisa 'não prática', puras configurações de interesses técnicos intersubjectivos postos em comunidade, um domínio objectivo de bens acerca de cuja utilidade, no exterior da teoria, nada é questionado e que, em todo o caso, originariamente, não fornece nenhum motivo para a apreciação e o engendramento de tais valores. De facto, os problemas e as teorias cosmológicas, que primeiro dominaram o interesse (...) moviamse em alturas abstractas que deixavam muito abaixo de si todos os domínios da praxis humana» ${ }^{18}$.

No entanto, e Husserl reconhece-o, «o voltar-se filosófico para a praxis, por conseguinte, a sua inclusão no interesse teórico indica, em referência histórica, o ponto mais significativo do desenvolvimento filosófico, na medida em que só através desta viragem foi motivada a fundamentação da Lógica e da Filosofia sujeita a normas pela Lógica» ${ }^{19}$. Uma praxis governada pela razão e pela lógica e já não por ritos e mitos

\footnotetext{
${ }^{16}$ IDEM, «Tipos formais da cultura no desenvolvimento da humanidade», p. 107

17 IDEM, p. 134.

${ }^{18}$ IDEM, «Tipos formais da cultura no desenvolvimento da humanidade», p. 108.

${ }^{19}$ IDEM, ibidem, p. 108.
} 
de origem, eis ainda o que deve a Europa aos filósofos Gregos: uma sabedoria racional e o gérmen para o desenvolvimento da Ética.

E. Lourenço, no texto atrás referido procura também consciencializar-nos, a nós Europeus, que «todas as culturas salvo a nossa, existem em função de umas respostas, de uma crença ou discurso mítico, fonte de uma familiaridade com o tempo que os europeus desde Heraclito e Píndaro, mas sobretudo desde Santo Agostinho, nunca conheceram» ${ }^{20}$, o tempo dos Deuses.

Mas voltando a Husserl e suas teses quanto à natureza da Europa: o que caracteriza a humanidade europeia, a sua identidade e diferença relativamente a outras formas culturais é a filosofia, enquanto descoberta e tematização da universalidade em sentido estrito. Daí que devamos dizer: «a Filosofía não é europeia. Pelo contrário, é a Europa que é filosófica. «O nome Europa designa evidentemente a unidade de um viver, de um trabalhar, e de um criar espirituais.» ${ }^{21}$ Isto é, uma atitude peculiar de ver o mundo, que foi transmitida pelos gregos. E o filósofo previne-nos: a grandeza da Europa filosófica, o seu estatuto de «arconte « da Humanidade não se confunde com qualquer projecto de domínio protagonizado por um povo, mas com o modo de como ela, na finitude das suas formas de cultura, é o fenómeno da ideia infinita de uma cultura racional que pode, sem limites, tornar-se a cultura de uma Humanidade universal» ${ }^{22}$. Com efeito, esta atitude peculiar de ver o mundo e de agir intencionalmente, a theoria, que não é comum a todos os povos, pode vir a tornar-se comum, uma vez que todo o homem deseja saber, aspira ao saber, como já o dizia Aristóteles. Em suma, a atitude teórica, que preside à Europa, é governada pela procura do logos comum, que pode ser alcançado e assimilado por qualquer um, pelo simples facto de ser um humano.

É a defesa filosófica desta razão comum, apesar das particularidades culturais dos povos, que Husserl designa por espírito da Europa: esse sentido da viagem ou alcance intencional de um olhar que sabe ultrapassar fronteiras e ir das árvores à floresta, no sentido da verdadeira theoria. Educar um povo neste tipo de razão, foi o mérito dos gregos, formando-o numa forma de pensar e de bem escolher. A própria phronesis ou prudência, cunhada por Aristóteles, como o primeiro grande modelo do agir ético ocidental, exige $a$ theoria, a meditação que implica a persistência de um olhar dirigido para longe e o culto da abstracção, resultado da visada teorética da alma. A theoria e a philia, esta enquanto momento fundamental da praxis, dirá Aristóteles, constituem justamente aquilo que

${ }^{20}$ LOURENÇO., E., op cit p. 8.

${ }^{21}$ HUSSERL, E., «A crise da humanidade europeia e a filosofia», p. 164. 
permite a realização da natureza humana, isto é, a sua felicidade ou eudaimonia. A teoria é por excelência a actividade do filósofo, no entanto, ela não corresponde de modo nenhum ao mito do filósofo isolado e solitário. «A felicidade aristotélica pressupõe uma colaboração entre filósofos, realidade que o Estagirita viveu em parte na Academia de Platão e no Liceu». A teoria não pode, na opinião de alguns dos seus comentadores $^{23}$, prescindir da philia, mesmo se a sua actividade teorético contemplativa é excelente. É que o homem autónomo precisa de amigos, não dos amigos úteis, mas virtuosos, porque ele não é nunca completamente autónomo e é-lhe impossível ser auto-suficiente ${ }^{24}$.

Quando a este olhar teorético se vem juntar o elogio do infinito trazido pela expectativa messiânica cristã e o conjunto de pressupostos implicados na passagem da pessoa divina à pessoa humana, temos o núcleo da intriga europeia, a expectativa de uma humanidade nova. O homem europeu considera-se doravante, lembra-nos J.F. Mattei, como pessoa, «não no sentido teatral do grego prosopon ou do latim persona que designava a máscara dos actores e o seu papel mas no sentido moral que permite a cada indivíduo afirmar a sua dignidade». A identidade do homem europeu surge dessa presença interior do ser razoável, que Kant mostrou ser fim em si. «Mas se o ser razoável é uma pessoa e não uma coisa, é na medida em que o pensamento europeu, ao receber a marca dupla da filosofia grega e da teologia cristã, inscreveu na alma esta distância de si a si e também ao outro, que faz de cada um de nós algo que nenhum olhar ou gesto sabe esgotar» ${ }^{25}$.

De acordo com J.F.Mattei, mesmo aquilo que caracterizou a Europa, no bom e no mau sentido, «as explorações da Terra pelos viajantes e as auscultações do coração pelos escritores não têm senão uma e a mesma origem: o alcance de um olhar que ultrapassa os seus limites para procurar, para além do seu horizonte o que acalmará a sua inquietude» ${ }^{26}$.

22 ALVES, P., «Introdução» à tradução portuguesa de Husserl, Europa: crise e renovação, p. 11.

${ }^{23}$ Cfr., FIASSE, G., L'autre et l'amitié chez Aristote et Paul Ricoeur. Analyses éthiques et ontologiques. Louvain Paris, Ed., Peters, pp. 174-175.

${ }^{24}$ Cfr. IDEM, ibidem, p. 173.

${ }^{25}$ MATTEI, J.F., Le regard vide. Essai sur l'épuisement de la culture européennne. Paris, Flammarion, 2007, p. 58.

${ }^{26}$ IDEM, ibidem, p. 31. 


\section{Crise da Filosofia e crise da Europa: alguns pontos de vista}

Ora, é evidente que se o mundo europeu nasceu deste tipo de razão ligada ao advento ético político da cidade, isto é, do espírito da filosofia, a actual fuga à filosofia, num mundo governado, cada vez mais pelo império da razão calculadora e económica e pela redução do compreender ao ver, confirmar e palpar, compromete o próprio desenvolvimento da viagem intelectual europeia. Tal é a segunda grande tese desta conferência de Husserl sobre A crise da humanidade europeia e a filosofia, nos anos vinte do século passado.

«As nações europeias estão doentes, a própria Europa, diz-se está em crise. Estamos a ficar, decididamente submergidos por uma maré de propostas de reforma ingénuas e exaltadas» ${ }^{27}$. A crise da Europa, de que E. Husserl nos fala neste conferência, não é a crise económica dos dias de hoje, mas aquela que precedeu a segunda guerra mundial. Como o filósofo o explicitará, é a crise das bases filosóficas do olhar europeu que, convertido ao cientismo do olhar de narciso, próprio do sujeito moderno, acaba por ser dominado pelas vendas do pragmatismo utilitarista, que chega até aos nossos dias.

Hoje, um século depois de Husserl, assistimos justamente à própria crise da economia europeia e com ela à crise da modernidade. E isto faznos meditar. E nomeadamente perguntar: se a crise da Europa é, em primeiro lugar, uma crise espiritual, e se toda a crise é caracterizada por uma alternativa especifica: confiança vs. desconfiança, será que uma resposta deste tipo poderá ainda salvar a Europa? Que resposta dar à crise num mundo, como o de hoje em que a filosofia parece uma ciência menor? Conseguirá ainda a filosofia manter o sentido da confiança na viagem do olhar, num mundo globalizado como o nosso, isto é, seremos ainda capazes de olhar para fora, com sentido? Ou estaremos a cair na tentação de destruir a abertura universal do nosso espírito, cujo alcance teórico e realização prática fundaram mesmo a dignidade do homem e seus direitos fundamentais?

O processo iniciado pela modernidade de «redução radical do sentido (imanentização) às condições transcendentais do sujeito, acabou por reduzir o olhar a Narciso. Àquele que só faz experiências do que ele mesmo pré-programa, e que consegue erradicar com a sua nova concepção do saber - saber para poder, prever e dominar - a ideia de transcendência, a identidade da visada teórica da Europa, aquela que tinha inventado um universal que pressupunha a palavra e que tinha reflexos sobre o fenómeno

${ }^{27}$ HUSSERL, E., «A crise da humanidade europeia e a filosofia», p. 120. 
social, que permitia a comunidade e a diferença e nada tinha a ver com o sentido da verificação científica e técnica.

A crise da Europa radica, segundo Husserl num racionalismo extraviado $^{28}$. O que é que o filósofo quer com isto dizer»? Corresponderá o seu diagnóstico da crise a mero saudosismo ou apresenta-nos Husserl uma proposta filosófica consistente? Ouçamo-lo para já no seu diagnóstico da crise: « (...) concedemos de boa vontade que a forma de desenvolvimento da ratio, enquanto Racionalismo do período do Iluminismo, foi um extravio, se bem que, ainda assim, um extravio compreensível» ${ }^{29}$.Com efeito, a partir da modernidade, imperou o pensamento calculador que, sob o olhar de Narciso, transformou o mundo ocidental e todo o significado da viagem teorética: o saber, o ideal da vida teorética tornou-se investigação $0^{30}$ inspectiva e de preferência de laboratório.

A irrupção da moderna ciência da natureza no séc. XVII, deu de facto origem, explicita Gadamer, na mesma linha, a uma mudança crucial no estilo do pensar ocidental. Ela promoveu simultaneamente a posição soberana do sujeito e a redução do mundo a representação deste. O solo filosófico em que emerge o cogito é de facto o do pensamento calculador, o tal extravio do racionalismo a que Husserl se refere, isto é o aparecimento de um modo de compreensão segundo o qual «a investigação dispõe do ente», por meio de uma representação explicativa ${ }^{31}$. É a época do mundo reduzido a quadro diante de um sujeito, que detém as suas categorias explicativas e que por meio de um cálculo pode tornar-se dono e senhor dele.

Reduzido a puro cogito, isolado, sem corpo nem tempo, o homem moderno, autónomo, desvincula-se de toda a comunidade da theoria, esquece a philia e converte-se em puro investigador e experimentador. E a investigação das ciências da natureza, com a sua lei primordial, a da especialização, desfaz progressivamente, desde que surge até aos nossos dias, «o compromisso de um equilíbrio com aquele outro tipo de conhecimento que é inerente ao ser humano, aquele que determina a sua existência pessoal e privada e ainda os seus passos como ser social que está, enquanto tal, marcado pelo poder da tradição» ${ }^{32}$.

Por outras palavras, perdeu-se o núcleo originário do conceito de teoria. E esta reduziu o seu horizonte, ao que está perante o olhar inspectivo, passando do sentido da vida para o laboratório. Converteu-se,

\footnotetext{
${ }^{28}$ HUSSERL, E. op cit, p. 141.

${ }^{29}$ IDEM, ibidem, p. 141-142.

30 GADAMER, H.-G., op.cit. p. 29

${ }^{31}$ RICOEUR,P., Le conflit des Interprétations. Essais d'herméneutique, Paris, 1969, p. 226.

32 Cf., GADAMER, H.G., Das Erbe Europas, Frankfurt, Suhrkamp, 1990, p. 97.
} 
enfim, na investigação especializada e segura da natureza, em ordem a uma aplicação técnica futura. A natureza transformou-se em reservatório de forças a explorar e a filosofia em epistemologia ou filosofia da ciência. Com isto a figura tradicional da filosofia como amor pela sabedoria e a da sabedoria prática, governada pela phronèsis e pelo ideal da philia desaparecem pura e simplesmente do horizonte e, em consequência, a relação entre filosofia e ciência inverte-se passando a ciência a condutora da felicidade da humanidade. Ainda hoje, apesar do desencanto já vivido e sentido face aos desaires provocados pela ciência, entretanto tornada tecnociência, não sabemos por vezes que papel dar à filosofia. Vemos, no entanto, como ela retorna com as suas grandes perguntas com o boom da ética nas várias profissões especializadas que hoje dominam o agir do homem.

Vivemos com efeito, num mundo cada vez mais dominado pela importância pública da nova ciência e pelas transformações do agir que as suas aplicações técnicas têm introduzido nas nossas sociedades. Não podemos negá-lo: assumimos desde a nossa Modernidade, um sentido novo, cada vez mais estrito, mais seguro e especializado do saber e com ele uma nova ideia de teoria. Este saber concebe-se a si mesmo muito mais como um poder fazer, um poder operar com eficácia no mundo circundante e já não como viagem ou eros, no sentido tradicional da theoria. Este poder invade hoje todos os sectores da vida humana tendo também os seus reflexos políticos, éticos e sociais.

A ideia de confiança na viagem que marcava a filosofia, dissolveu-a a moderna ciência experimental ao tentar, com os seus novos poderes, realizar totalmente o visado dessa confiança: uma libertação total do homem pelas suas próprias mãos. A palavra «sistema», diz-nos a este respeito, Gadamer, entrou nos finais do séc. XVII, na linguagem da filosofia para designar a nova relação da ciência com a antiga metafísica ${ }^{33}$.

A ciência moderna, converteu-se numa forma de saber que pouco ou nada tem já tem a ver com o antigo conceito de sabedoria. Representa, pelo contrário, uma forma de conhecimento orientado quase exclusivamente para o poder fazer, para o domínio e manipulação da natureza. A teoria como investigação, transforma-se finalmente no grandioso empreendimento de penetração segura da mão humana em âmbitos desconhecidos do mundo. Domínio que, como sabemos, alargou de tal forma o âmbito do poder fazer humano que este é capaz de se converter hoje em faber hominis .

Podemos, com efeito, dizer que pela primeira vez na história da humanidade, dispomos de um saber que nos permite exercer um poder sobre a natureza, sobre a vida e sobre a morte, isto é, sobre o que

33 IDEM, ibidem, p. 113 
antigamente fugia à nossa alçada e era considerado fatalidade. Passamos, como nos A. Jacquard, do papel passivo de espectadores facilmente iludidos pelas aparências ao de actores capazes de alterar todo o andamento da cena. A todos os níveis podemos hoje intervir e manipular. Parece-nos mesmo que tudo é possível ou poderá vir a sê-lo em breve! A própria natureza, outrora o nosso árbitro, caiu-nos subitamente nas mãos! Alterámos os limites naturais, nomeadamente, os do nosso próprio corpo; não sabemos mesmo se há limites, tão variadas que são as possibilidades de manipulação deste, de acordo com a sua nova compreensão como «produto contingente natural, modificável, de facto e de direito $^{34} \gg$.Vejamos, por exemplo, o caso das ciências da vida, onde as novas técnicas da reprodução, da genética e do sistema nervoso interferem em zonas outrora inacessíveis à acção humana e provocam experiências imemoriais da nossa passividade, ligadas nomeadamente à nossa hereditariedade. Vejamos também o do mundo social ou âmbito da praxis: a ciência chega hoje ao ponto, todos o sabemos, de planificar a vida social a partir de bases puramente calculadoras, excluindo toda a possibilidade da amizade em prol de valores como os da rentabilidade, da eficácia, do progresso e da qualidade material de vida. Por isso, substitui toda a formação praxiológica - essa coisa tão pouco palpável e verificável, cada vez mais estranha ao homem contemporâneo, - pela aprendizagem rápida de competências e mecanismos automáticos que reduzem os sujeitos à figura do trabalhador. Assim se perdeu, de forma quase definitiva, o que nos era oferecido pelo antigo conceito de teoria e assim se esqueceu a dimensão transcendente do olhar europeu. Para a ciência moderna, o mundo é horizontal, reduz-se à paisagem; o olhar perde toda a dimensão de mistério e o universo é compreendido a partir de uma divisão binária em sujeito e objecto. O sujeito é todo-poderoso, verdadeiro narciso e o objecto meramente inerte.

Mas o sujeito autónomo da modernidade, aquele que sucede ao homem interior de outrora, acabou por vir a revelar-se um homem vazio. Como nos diz E. Lourenço, no texto, já referido: «Seja como for a Europa já não vive o seu tempo próprio com aquela paixão inquieta e inquietante, poderosamente aspirada pelo futuro que parecia deportá-la para além de si mesma (.....). Esta espécie de psicodrama da cultura europeia e da melancolia que dela se exala, são por assim dizer o resumo da ilusão europeia por excelência: a de se identificar com uma temporalidade que revelando quer de uma Fé de alcance universal, quer da universalidade mesma da razão, podia dar conta de tudo, mesmo do mistério ou do enigma

34 JACQUARD, A, Ensaio sobre a pobreza. A herança de Francisco de Assis, trad. Lisboa, Europa-América, 1997, p. 54 
da história (....) Só a cultura europeia pretendeu que o tempo de Deus fosse o dos homens. Quando este desafio prometeico perdeu a sua razão de ser, o homem tendo-se tornado para si um fardo mais pesado do que Deus, a nossa sede pareceu extinguir-se» ${ }^{35}$.

Também Freud, já nos finais do séc. XIX, anunciava em $O$ mal-estar da civilização que o homem contemporâneo é infeliz, apesar dos seus progressos técnicos e de se ter igualado a Deus. Por sua vez, Charles Taylor, na sua obra, $O$ mal-estar da modernidade põe em causa o narcisismo das sociedades contemporâneas e aponta três motivos fundamentais para o dito mal-estar : a) o primeiro é o individualismo exacerbado a que a técnica conduziu, individualismo que desenraíza o homem da ordem social, da ordem cósmica e da ordem religiosa, cortando-o dos seus antigos valores morais; b) o segundo, diz respeito à razão instrumental, que tendo-se desembaraçado de uma razão substancial, ordenada segundo fins, satisfaz-se apenas com os meios e procedimentos técnicos. Tudo passa a ser instrumentalizado, seja o homem, seja a máquina ou a sociedade; c) o terceiro motivo, reside no atomismo dos indivíduos que, face a um Estado burocrático e impessoal, se refugiam nos seus prazeres privados em detrimento da sua implicação comum enquanto cidadãos. Taylor resume então o mal-estar da civilização nestes termos: uma perda de sentido causada pela desaparição dos horizontes morais; o eclipse dos fins; a perda da liberdade causada pela renúncia à própria implicação na cidade.

E temos mais: a crise do saber que Husserl diagnosticava, no princípio do séc. XX, agravou-se entretanto, tomando mesmo uma nova forma. Passámos da compreensão pela palavra, com tudo o que isso implica de esforço, diálogo e interpretação, para o modelo do informar-se vendo. Somos, de facto, nos dias de hoje, mais homo videns do que homo sapiens. Para Husserl era o objectivismo e o naturalismo que prejudicavam a viagem da racionalidade. Hoje, a crise da palavra, como símbolo que se traduz inteiramente no que significa, logo que exige interpretação, afecta todo o saber. A palavra traduz-se, e só se traduz, se compreendemos a língua a que pertence, enquanto a imagem vê-se simples e passivamente. Daí a sua facilidade. Podemos mesmo dizer que chegámos ao estádio último estádio do positivismo epistemológico, ao ponto em que as suas próprias vendas mentais se exacerbam até liquidar o saber que, no entanto ele queria libertar. Nestas condições, a tarefa da filosofia não é hoje, como pensava Husserl, a procura da autenticidade do saber na sua relação com a vida e com a humanidade. Trata-se antes de pensar as condições da

35 LOURENÇO, E., op. cit., pp. 8-9. 
manutenção exercício do saber ${ }^{36}$. Este enfrenta hoje uma situação que Husserl não poderia imaginar: a própria possibilidade do seu desaparecimento, a sua substituição pelo entretenimento numa sociedade marcada pelo império do vídeo ver, pela ausência de consenso, e já dividida entre tradição, modernidade e pós-modernidade.

III. Da erosão contemporânea do saber ao novo papel da sabedoria: o papel da Filosofia na Europa de hoje.

É necessário pois pensar a articulação da filosofia com a condição de possibilidade do pensar por conceitos e palavras e com a manutenção da Europa, como pátria da sabedoria. É necessário esclarecer os meios de renovação desta articulação, tendo em conta a situação pragmática e política do saber nas sociedades mercantis contemporâneas ${ }^{37}$. Não esqueçamos que a racionalidade económica dos dias de hoje, substitui a formação cultural pelo espectáculo cultural e pela comutação dos bens. É para ela muito estranha a lógica que presidia aos vários domínios do agir humano: a política, a arte e a educação. Com efeito, lógica económica nivela o agir humano, domina todos os sectores da vida humana, por meio de um sistema de troca mercantil generalizada. Satisfaz-se com o próprio declínio da racionalidade e com a decadência da sua capacidade teórica. A cultura mediatizada das nossas sociedades - atenção: a mediatização da cultura mais não é do que a sua mercantilização - forma uma cultura lisa, unificada, aparentemente sem problemas, altamente cultura de entretenimento e cuja qualidade mediática de espectáculo tem justamente como intuito apagar toda a sua dimensão filosófica ou problemática ${ }^{38}$.

Perante esta situação quais então os desafios novos para o filosofar? Não deixar que o seu saber ético e crítico originário desapareça, face ao domínio de saberes meramente orgânicos, apostando para isso na sua transmissão conseguida. Isto é num movimento de revitalização da herança espiritual eclipsada pela modernidade. Se a lógica mercantil anula o tempo, se ela se define e realiza como uma pura simultaneidade, se o seu ponto fraco é mesmo o tempo, as questões a ele associadas e a ideia de duração, é por aqui que a Filosofia pode intervir. Falta-nos hoje perceber a estrutura linguageira ou narrativa da nossa experiência vivida do tempo, não a do

${ }^{36}$ CAYE,P.« La tâche de la philosophie à l'épreuve de l'unification européenne »in WEIL,N., ed , Existe-t-il une Europe philosophique, Rennes, Presses Universitaires de Rennes, 2005, p. 278.

37 IDEM, ibidem, p. 278.

${ }^{38}$ IDEM, ibidem, p. 282 .. 
tempo medido pelos relógios do mundo, mas o da memória e cultivar a paciência diante do que, contudo, nos assalta e dura. Apesar do imediatismo mediático do mundo da eficácia e da prontidão em que vivemos, há fenómenos centrais das nossas vidas que escapam ao império do carregar no botão e da imagem. Dependem, pelo contrário, do desenrolar do tempo e da duração, afirmam-se na duração, categoria que temos vindo rapidamente a evacuar. Por exemplo a própria ipseidade, que nos constitui e distingue do animal, aquela que não se reduz à nossa identidade meramente biológica, faz-se numa história de vida, com outros, leva tempo, exige a memória e a responsabilidade, cujo suporte é a atestação destas capacidades no tempo vivido e na sua expressão (construção) narrativa. Pensar a estrutura narrativa da memória, da relação e imaginação humanas representa para o Filosofar, dos dias de hoje, reabilitar uma das materialidades da transmissão humana do sentido, que resiste ao individualismo da imagem, o muthos e a sua mimese temporal do real. E, reabilitar a tríade da Poética de Aristóteles, muthos, mimese, catarse, como núcleo do fenómeno da transmissão e da recepção humana do sentido, pode levar o homem a abandonar o papel passivo de espectador isolado que hoje assume perante os media. De espectador a intérprete ou tradutor, tal é o caminho de uma luta, contra a passividade, como modo humano de ser, que cabe à Filosofia travar, em ordem a poder reconstruir uma consciência partilhada do vínculo simbólico representado e instituído com os outros. ${ }^{39}$

Construir o tempo, como estrutura da alma, construir a duração é justamente saber herdar e saber transmitir. É porque a transmissão e a duração, que aquela instaura, são capazes de dispensar a lógica do ver e do poder, e de assumir a renovação das heranças do passado, nas avarias do sistema e, melhor ainda, de retomar o que o sistema, pela sua própria impossibilidade de plena realização, deixa cair, que elas introduzem no próprio sistema uma diferença positiva, irredutível ${ }^{40}$ : a do pensar que poetiza ou do poema que pensa. O tempo vivido, os seus enredos, dramas, alegrias e questões fundamentais e o modo de os dizer e compreender, eis a grande tarefa da filosofia contemporânea, que sabe que há algo no homem que escapa ao ver e que sabe ainda como o imaginário europeu foi sendo construído por figuras literárias chave que se reflectiram na própria aventura filosófica, já desde o tempo dos gregos.

A esta tarefa de renovação da palavra, por meio de uma meditação sobre as experiências humanas que não encontram tradução na tecnociência, e se mantêm como questão, apesar da cultura lisa do nosso tempo,

39 AUGÉ, M., Para que vivemos? Trad., Lisboa, 90 graus editora, 2006, p. 86.

${ }^{40}$ CAYE, P., op. cit., p. 286. 
se dedicam alguns filósofos da actualidade, nomeadamente P. Ricoeur com as suas obra Temps et récit e A tradução. À representação mediática da acção, o filósofo contrapõe a representação mimética, histórica ou literária, para poder relançar, contra o primado do económico, o imaginário simbólico, metafórico e narrativo, como espaço de experiência de uma renovação do laço social e de uma purificação das paixões humanas, nomeadamente a da estima de si e assim promover o difícil caminho do reconhecimento como figura de um ser marcado pelo tempo vivido e pela palavra, logo pela transmissão hermenêutica, que exige o esforço da palavra e da tradução. Quanto à hospitalidade da tradução, Ricoeur afirma-a como acto de confiança e relação, contra a alienação provocada pela separação das línguas. A bênção de Babel afirma o significado positivo da diferença humana e significa a renúncia ao mito da tradução única e perfeita. Toda a tradução é pelo contrário a construção de algo comparável ${ }^{41}$ e nela está implicado um modelo de vida em comum, de co-habitação num mundo tornado familiar pela troca narrativa de memórias e pela convivialidade da interpretação.

O movimento hermenêutico de transmissão e de apropriação de símbolos, que possam relançar a vinculação inter-humana, porque são comuns à poética da acção humana é uma das apostas possíveis, que pretendem responder ao desnorte ético da Europa contemporânea. Por meio dele encontramos ainda o de Eranos outra das possibilidades que hoje se nos oferecem para contrariar a ordenação do tempo humano que hoje cabe aos media fazer, nomeadamente ao televisor.

Eranos, palavra grega quer dizer «uma reunião, uma celebração comum, um banquete no qual os participantes contribuem com um dom, um presente, ou no caso da Escola Eranos, fundada a partir de 1933, com uma comunicação voluntariamente oferecida $\gg^{42}$. Implicação de si numa causa que possa estabelecer uma nova mediação das representações sociais que já entraram em crise quando a Crise se anuncia, eis a mensagem que nos lega este movimento que, por sua vez nos faz pensar na crise da modernidade e nas suas saídas simbólicas possíveis.

Terminemos este texto pela indicação das três grandes tarefas que cabem, segundo Ricoeur, à filosofia no mundo contemporâneo: a) a preservação e transmissão hermenêutica do património imenso de questões que nos foi deixado pela história da filosofia; com efeito, nas nossas sociedades pluralistas parece acontecer para estas tradições uma nova

\footnotetext{
${ }^{41}$ RICOEUR, P., Sur la traduction, Paris, Bayard, 2004.

${ }^{42}$ SHCABERT, T., «Une herméneutique intercivilisatrice: 1'école d'Eranos», in WEIL, N., ed , Existe- $t$-il une Europe philosophique? p. 297.
} 
oportunidade de reinterpretação; b) a abertura às ciências e ao espírito científico, isto é, às suas metodologias, ao seu dinamismo e à sua linguagem; c) finalmente enquanto prática da teoria e frequentemente ligada ao uso público do discurso, no âmbito da formação universitária ou no mundo da edição, cabe-lhe efectuar uma reflexão desinteressada sobre os aspectos éticos da acção. Esta reflexão é hoje solicitada pela medicina, direito, pelos media e mesmo pela política. Surge pois a ocasião «para que o filósofo se considere a si mesmo como um cidadão que se interroga sobre o lugar da filosofia e sobre o seu lugar próprio no seio da cidade» ${ }^{43}$.

O lugar do filósofo hoje em equipas multidisciplinares, em que se reflecte sobre a difícil aplicação dos saberes, situa a filosofia e a sua fecundidade para a Europa entre a necessidade do pensamento especulativo ou teoria, sob pena de sucumbirmos aos saberes meramente técnicos, e a sabedoria prática ou os seus prudentes conselhos em situações de incerteza. É «o justo equilíbrio entre estas duas tarefas que pode assegurar para à filosofia um futuro digno do seu passado multimilenar» ${ }^{44}$, lembra-nos o filósofo.

${ }^{43}$ RICOEUR,P., «Les trois tâches de la philosophie», in Rue Descartes, Revue du Collège international de philosophie. L'homme capable. Autour de P.Ricoeur, Paris, Puf, 2006, p. 11.

${ }^{44}$ IDEM, ibidem, p. 12 . 